Western University

Scholarship@Western

Aboriginal Policy Research Consortium International (APRCi)

2012

Measuring cultural appropriateness of mental health services for Australian Aboriginal peoples in rural and remote Western Australia: a client/ clinician's journey

Kerrie Doyle

Follow this and additional works at: https://ir.lib.uwo.ca/aprci

Part of the Other Mental and Social Health Commons

Citation of this paper:

Doyle, Kerrie, "Measuring cultural appropriateness of mental health services for Australian Aboriginal peoples in rural and remote Western Australia: a client/clinician's journey" (2012). Aboriginal Policy Research Consortium International (APRCi). 366.

https://ir.lib.uwo.ca/aprci/366 
This article was downloaded by: [University of Western Ontario]

On: 18 July 2012, At: 10:59

Publisher: Routledge

Informa Ltd Registered in England and Wales Registered Number: 1072954 Registered

office: Mortimer House, 37-41 Mortimer Street, London W1T 3JH, UK

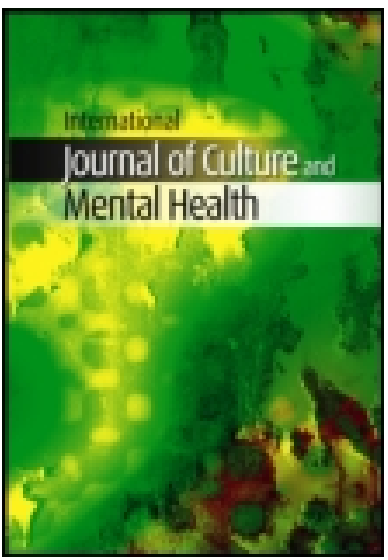

\section{International Journal of Culture and Mental Health}

Publication details, including instructions for authors and subscription information:

http://www.tandfonline.com/loi/rccm20

\section{Measuring cultural appropriateness of mental health services for Australian Aboriginal peoples in rural and remote Western Australia: a client/clinician's journey}

Kerrie Doyle ${ }^{a}$

${ }^{a}$ Faculty of Health, University of Canberra, Australia

Version of record first published: 26 Jul 2011

To cite this article: Kerrie Doyle (2012): Measuring cultural appropriateness of mental health services for Australian Aboriginal peoples in rural and remote Western Australia: a client/clinician's journey, International Journal of Culture and Mental Health, 5:1, 40-53

To link to this article: http://dx.doi.org/10.1080/17542863.2010.548915

\section{PLEASE SCROLL DOWN FOR ARTICLE}

Full terms and conditions of use: http://www.tandfonline.com/page/terms-andconditions

This article may be used for research, teaching, and private study purposes. Any substantial or systematic reproduction, redistribution, reselling, loan, sub-licensing, systematic supply, or distribution in any form to anyone is expressly forbidden.

The publisher does not give any warranty express or implied or make any representation that the contents will be complete or accurate or up to date. The accuracy of any instructions, formulae, and drug doses should be independently verified with primary sources. The publisher shall not be liable for any loss, actions, claims, proceedings, demand, or costs or damages whatsoever or howsoever caused arising directly or indirectly in connection with or arising out of the use of this material. 


\title{
Measuring cultural appropriateness of mental health services for Australian Aboriginal peoples in rural and remote Western Australia: a client/clinician's journey
}

\author{
Kerrie Doyle* \\ Faculty of Health, University of Canberra, Australia \\ (Received April 2010; final version received November 2010)
}

\begin{abstract}
Aboriginal and Torres Strait Islander people in Australia suffer from poorer mental health than non-Aboriginal people, especially in remote and rural settings. Even with the ongoing adoption of the World Health Organisation's 'Closing the Gap' recommendations, the determinants of mental health, including suicide rates, hospitalisation rates and access to healthcare are not noticeably improving. One of the issues for this gap is the poor cultural proficiently of mental health services, creating a cultural security threat to the workers and service users. In my work as a senior Aboriginal Mental Health worker, I have observed incidents of ongoing cultural incompetence across the spectrum of healthcare. This embeds institutionalised racism that in turn fosters poor mental health. I offer examples of operational cultural proficiency and make recommendations to increase the appropriateness of services for Aboriginal people.
\end{abstract}

Keywords: Aboriginal mental health; cultural proficiency measurement; remote and rural mental health; closing the gap; ATSI

\begin{abstract}
Aboriginal mental health status
Australian Aboriginal and Torres Strait Islander peoples make up approximately 2\% of Australia's population (Australian Bureau of Statistics, 2010). Even with this comparatively small demographic, we have long had higher levels of acute morbidity and mortality from mental illness, assault, self-harm and suicide; higher levels of alcohol and other drug use; and more frequent contact with the criminal justice system than other Australians. Levels of child abuse and neglect are higher, while education, employment and income are lower for Aboriginal Australians (Australian Health Ministers' Advisory Council, 2008). The Committee for the Social Determinants of Health of the World Health Organisation (WHO) clearly identify education, childhood safety and high degrees of imprisonment as determinants of mental health for individuals and communities (WHO Social Determinants of Health Commission, 2008). With this matching of predictors of social and emotional distress defined by the WHO, it is not surprising then that Aboriginal peoples suffer from poor mental health. Further, trend data suggests the burden of disease for mental health issues is increasing rather than any amelioration occurring (Gorman \& Ward, 2008). However, in order to provide evidence to base interventions, it is important to collapse such indicators over a holistic approach.
\end{abstract}

*Email: Kerrie.Doyle@canberra.edu.au 
An initial consideration needs to be the inability of Aboriginal people to access services that are appropriate in a timely and affordable manner (O'Brien, 2006) or even adequate. 'Adequacy' is defined as ' $(\mathrm{t})$ he state or quality of being adequate, proportionate, or sufficient; a sufficiency for a particular purpose; as, the adequacy of supply to the expenditure' (Webster, 1913). Operationally, it means the ability of a service to meet a particular, peculiar need. This value of measurement is equivocal and therefore needs quantitative and qualitative measures to identify service gaps (Brideson, 2004). It is challenging to decide 'fit for service' activities when the services are not viewed through an Aboriginal lens. This results in insufficient culturally respectful mental health services' (Berry \& Crowe, 2009). Cultural competency can only be defined and evaluated by the members of that cultural group, as Ramsden (Papps \& Ramsden, 1996) stated almost a decade ago.

Recognizing the need to measure these services and programs, the Aboriginal and Torres Strait Islander Health Performance Framework (HPF) was developed under the auspices of the Australian Health Minister's Advisory Council. The HPF is designed to inform policy analysis, planning and program implementation using national trend data across a variety of indices. The Report provides high-quality contextual data on progress in outcomes towards the Council of Australian Government's 'Closing the Gap' agenda (Australian Health Ministers' Advisory Council, 2008).

\section{Defining the data}

From the data sets created, there is no item that distinctly measures 'cultural appropriateness'. Each client or service user has individuated care that is inherently supposed to incorporate cultural proficiency, yet there is no discrete variable to capture this information. However, in most unstructured evaluations within conversations, clients will often complain about a service being not 'Aboriginalfriendly' or they may feel uncomfortable accessing the service (Garvey, 2008). Given that identified services have not factored in 'culture' as a quality measure, it is unlikely mainstream services will capture this outside of client satisfaction rates or subjective data (Brunero, Lamont, \& Fairbrother, 2009).

In Western Australia (WA) data is collected from various data sources and described as belonging to one of the Commonwealth of Australia's 'Office of Aboriginal and Torres Strait Health' (OATSIH) Planning Regions (OPRs). In WA, there are eight discrete regions (Australian Health Ministers' Advisory Council, 2008). These regions usually have a major hospital and health centre, with diverse health structures around the region such as general practitioner practices, Aboriginal Medical Services and outreach services. Data is collected from these health services to identify use of services by Aboriginal clients and the Diagnostic Related Groups within each region.

This compound data indicates that standardised rates of Aboriginal people admitted to hospital for mental health conditions across my region is significantly higher than non-Aboriginal admissions, even factoring for non-identification of Indigeneity rates (Draper, Somerford, \& Pilkington, 2009) and, indeed, the rate of admission from WA is almost twice the standardised rate of other regions (Australian Health Ministers' Advisory Council, 2008). The need to transport individuals to the treating hospital and the fact that there is no such facility in regional WA demonstrates that Aboriginal people are not treated in their home 
communities and continue to present sicker and later (Raphael \& Swan, 1997) in a course of a disease episode, ending up in acute facilities thousands of miles from home. This occurs even though the WA Mental Health Act 1996 ensures mental health clients in WA are mandated to receive dignified best practice care, with the right to have treatment in their communities (WA Mental Health Act, 1996). However, considering the anecdotal evidence concerning the high levels of emotional and social illnesses of Aboriginal people, this rate would still appear to be low.

Problematically, this data is not always identified using a consumer's 'place of usual residence', so the OPRs with an inpatient unit will automatically score higher treatment rates than regions with no long-term in-patient facility. Also, the hospital separations data cannot be considered to represent individual consumer service interactions, as transfers inter-region count as two separations and, of course, one individual might have numerous admissions over a count period. Additionally challenging is the issue of small population numbers in some regions. Care needs to be taken to interpret these statistics with confidence. Nonetheless, from 1998/1999 to 2005/2006 there were no significant changes in hospitalisation rates for mental health conditions among Aboriginal people, whilst there were significant decreases for nonAboriginal people with an average yearly decline of 0.5 hospitalisations per 1000 (Australian Health Ministers' Advisory Council, 2008). This suggests a service that might not be appropriate or acceptable to the local Aboriginal population or that the number of mental health issues in the Aboriginal population is increasing or even that the data is now being collected in a more transparent manner.

Further data also suggest the rates of community mental health occasions of service are also higher for the Aboriginal community in some regions (Australian Institute of Health and Welfare, 2008). This does not include any data from NonGovernment Organisations (NGOs) and, in rural areas, these NGOs include a large number of community mental health service providers. The data from these organisations is not publicly available. However, with the introduction of Practice Improvement Payments to General Practitioners Practices (practices are paid a higher subsidy for caring for Aboriginal clients) and the ability to claim health checks and mental health care from Medicare, there are larger numbers of Aboriginal people accessing community services in the 2006 data than in the 2003 data (Australian Health Ministers' Advisory Council, 2008).

Over the period 1992-2002 the age-standardised suicide death rate for Aboriginal people in WA was higher than the average national rate for 6 of the 11 years. Data representations of higher rates of suicide in WA are likely the result of a high ratio of urban-to-remote areas and a high proportion of discrete Aboriginal populations. Suicide rates amongst Aboriginal males in 2006 were more than double those of all males in the State (39.3 versus 20.6 per 100,000 males, respectively). In WA, a quarter of the males and over half the females who completed suicide had previously attempted suicide and one third of males and two thirds of the female suicides had suffered from a diagnosed psychiatric disorder in the 12 months prior to their deaths. The most commonly diagnosed disorders were depressive disorders, schizophrenia, substance misuse, personality and adjustment disorders (Australian Health Ministers' Advisory Council, 2008), even though there is no diagnostic measurement tool reliable across cultures (Westerman, 2004).

Nonetheless, these data sets demonstrate that Aboriginal people are indeed accessing mental health services in WA and that they present with higher acuity and greater percentages than non-Aboriginal people for all categories of mental distress 
(Smith et al., 2008). The question then is: why isn't the data demonstrating a closing of the gap in morbidity and mortality rates and an easing of the burden of disease for mental health issues and clients in WA?

\section{Measuring cultural proficiency in mental health services}

Measuring quality in Australia is based on the ACHS accreditation standards, similar to the ISO standards. However, there is no stand alone accreditation item for cultural proficiency. Therefore area Mental Health Services (MHS) have no method of identifying adequacy outside of the TLAR method ('that looks about right'). While an attempt to marry 'Occasions of Service' or 'Length of Stay' with population percentages may seem intuitive, it is not statistically sound to compare these variables as it is not possible to extrapolate the extent of a mental health issue in the community from these data sets. Using Casemix data (data captured from public hospitals) is also problematic, as it measures the users of a service in that service's location and not necessarily the usual home address of the client and some Aboriginal people will give a local address to maintain their privacy, rather than their usual home address. For example, one service might claim they are meeting benchmark and therefore client satisfaction in delivering care to Aboriginal clients as these identified Aboriginal clients make up the same percentage as the local community group, however, in a regional setting, a lot of the clients might be referred in from outer regions. Currently, measuring 'Discharge against advice' is considered the most reliable measure of user satisfaction, although again it is not possible to tease out the issues for self-discharge and these data are not publicly available. Given that it is well known that Aboriginal people suffer mental health issues at a much higher rate than non-Aboriginal people (Wand, Corr, \& Eades, 2009), a higher admission rate would be expected. This leaves services that are committed to giving quality services in a quandary. Can qualitative data be used to determine effective service provision? If a service relies on user satisfaction rates, how valid is it to expect clients to determine the standards of a service (Maffei, Shea, \& Stewart, 2003)? Very few Aboriginal clients are health practitioners with professional knowledge enough to recognise elements of good care. Accreditation processes need to include measures of the organisation's ability to meet the needs of Aboriginal people or, rather, that measurement processes include demonstrated applied cultural appropriateness

\section{A clinician/client journey}

I work(ed) as the senior Aboriginal Mental Health Clinician across one of OPRs in WA. This role that covers both public services (Area Health Services), privatefor-profit hospitals and Aboriginal Medical Services (AMS), as well as private providers (GPs), not-for-profit organisations and any other organisation requesting my service. Whilst at times I take a load to case manage, I generally work in an advisory or supportive capacity. Also, there is one prison in the region, with a $90 \%$ Aboriginal prisoner population (although the demographic for Aboriginal people is not above $10 \%$ in this region). The prison houses both men and women. I visit rarely and then only on request of the public health physician who might have a 'problematic' Aboriginal client. This supposedly gives me the capacity to manage consistency and continuity across services and the region, notwithstanding this region is almost four times the size of Britain. 
Unlike most other areas of health service delivery, the quality of mental health service provision lies almost completely in the people staffing the service. There are many expert health practitioners in these services, who demonstrate social justice as a core value (Cleworth, Smith, \& Sealey, 2006). These nurses, doctors and allied health practitioners will advocate for appropriate treatments and services, often at a cost to their careers. However, these professionals will often complain to me of 'kicking against the pricks' and are constrained by finances, resources and institutionalised racism, thereby being unable to deliver a quality service. Sometimes they admit to not knowing what the appropriate care is at all. Examining the client experience as a journey might demonstrate issues of concern.

\section{The client's journey: before the hospital}

Usually the first step in a client's journey is assessment and pre-assessment. Assessment is intervention, as Rollnick's 'Early Intervention' model (as cited in Knudson, 2009) demonstrates, and needs to be taken carefully as it will inform the remainder of the client's therapeutic pathway by capturing the objective and subjective data that will inform the intervention pathway for that client. These assessments are meant to be rapid, as they are performed in a limited time and it can be challenging for clinicians (Haswell-Elkins, Sebacic, Hunter, \& Mar, 2007). However, when interviewing Aboriginal people it is important to plan for extra time, allow silences and get congruence with listening behaviours (e.g. posture, body language etc) (Shelton, 2010). It is important to not be offended by 'offensive' language, as Australian Aboriginal English differs from mainstream language and, indeed, is classified as a separate language (Australian Institute of Aboriginal and Torres Strait Islander Studies, 2010). However, I have noticed numerous occasions on which service has been delayed or even denied because of perceived 'aggression' from the client. It is also difficult to get some practitioners to allow extra time for Aboriginal clients, defending their position with that hoary chestnut 'I treat everyone the same'.

Clients will learn which person they can/not approach and will wait or refuse treatment from unsafe practitioners (Eley, Young, \& Hunter, 2007). This means that where there is a culturally proficient practitioner, the community are happy to attend and issues are sorted quickly. Where the practitioner is not respected in the community, treatment and intervention is not sought (Vicary \& Bishop, 2005). These practitioners will not use the Aboriginal Mental Health Workers (AMHW), even when the AMHW requests to be present or part of the assessment. Ergo, if the staff member is culturally proficient, the service delivered is good - if they are burnt-out and resentful for whatever reason, the assessment might not match the problem and treatment is compromised.

The issues of shame and stigma are a huge risk for Aboriginal people and communities (Jones, 2009). This needs to be carefully managed and explains why the ability of a practitioner to maintain confidentiality is paramount. The exclusion of some Aboriginal consumers, where are they kept at 'camp-fire' distance - effectively kept separate from the community - allowed to come within a distance where they can metaphorically 'see the campfire' is a real risk to post-discharge clients.

The number of staff is always problematic nowadays, with increasing pressure on the health dollar (Dunbar, Hickie, \& Wakerman, 2007). Unfortunately, my region has 'rationalised the female' AMHW position and expects one AMHW to cover the 
entire region. The male wadjilla (whitefella) psychologist at the AMS refuses to work with female clients and will send all the ladies to the Bringing Them Home (BTH) counsellor. This is at times appropriate, but the BTH counsellor was employed because she demonstrated the appropriate behaviours and attitudes (i.e. she's a nice person), but has no access to gaining the knowledge and skills that go behind it to make her therapeutic, even though the OATSIH-funding model insists all BTH counsellors access training in their initial year of employment, otherwise the employment grant is forfeited. This means that even though the preference in Aboriginal communities is to match gender of client to practitioner, when there is such a huge skill deviance and a refusal to serve means half of the population doesn't get treatment, even though 'on-paper' that community has a resident qualified counsellor! To offer another example of cultural incompetence, a non-Aboriginal psychologist asked me if she could go and work in the community, as she was 'darker' than me and 'looked' more Aboriginal. It is always unfortunate that the poor examples are maintained in community and individual memory than positive examples (Duke, 2007). This is where 'vouching' for a service in a community is so valuable and a community will not attend a clinic where the service is poor until there is no other choice. This is one reason why Aboriginal people present later and sicker, or just end up incarcerated as a result of unacceptable behaviours.

In the three months over Christmas, I 'found' three men from my home community in the local prison. They were arrested for crimes relating to use of alcohol (e.g. drinking in a public place, disturbing the peace). However, one of these men was well known to me and was on a community treatment order, but he hadn't 'picked up' (attended the health clinic for treatment as ordered by the courts) for at least three months. He relapsed and ended up fighting with a family member, was arrested and jailed. He didn't like the nurse in the clinic who used to complain about his smell, so he didn't go and get his monthly anti-psychotic injections. The other two had similar stories. The problem is these community clients are 'hostage clients' of a service. There is no alternative to the service within 100 kilometres and, with no viable transport options available to these clients, they disengage from the health care system and become more acutely unwell (Drury \& Munro, 2008). These men had drug (marijuana)-induced psychoses (Nagel, Robinson, Condon, \& Trauer, 2009), exacerbated by the lack of culturally appropriate mental health care (Lee, Clough, \& Jaragba, 2008).

This demonstrates the need for communities to have a controlling interest in their health service, even if it is not an identified AMS. The Aboriginal people of my home community are very generous and self-effacing. They have a lived experience of racism daily (Larson, Gillies, Howard, \& Coffin, 2007). There are high incidences of drugs abuse in Aboriginal communities (Knudsen, 2009), with my home community being no different. This is really abuse of self for young people with minimal hope for a better life (Lemstra, Neudorf, \& Mackenbach, 2008). There are no specialised drug and alcohol services in this community, merely a burnt-out nurse who often announces to staff and clients (and students, visitors etc) that he is only there for the money, an AMHW, who is not qualified in mental health and me - who gets to this community maybe once every four months. The nurse has recently installed a large glass partition in the clinic - after there was one issue of threatened violence. Now, all clients (and me too) have to come to the glass partition and almost yell (with no understanding that many Aboriginal people have high levels of hearing loss) - so there is no privacy in the clinic at all. Not many Aboriginal people will go and 
announce in a loud voice any symptoms they have. This is a very poor service to a large community with evidence of high levels of social and emotional distress. Clearly, potential clients will avoid a service with such an unwelcoming atmosphere as much as possible, even with worsening disease states (Geanellos, 2005).

\section{The client's journey: admission processes}

Aboriginal people are brought to the attention of the mental health services in various manners, including self-report, community concern and referral from other health professionals and/or the police (Hunter, 2007). Even though it is standard operating procedure, and there is no viable alternative, using police personnel as a first-line contact for mental health clients is fraught with difficulty. Undoubtedly with the best intents, this process of calling the police for mental health emergencies almost criminalises a mental health client. Each of these modes of admission into a mental health service will affect the rest of that client's therapeutic journey (Sheldon, 2001). Sometimes clients in the admission area appear to have been roughly 'encouraged' to attend the hospital. They end up either as heavily sedated as the Royal Flying Doctor Service transfers them out, or transported by road to the local regional hospital, hours away in the closest township.

The mental health room in the emergency department of the regional hospital is quite rightly built to keep staff safe. However, this means the client is kept in a room with no furniture or plumbing for anything up to 24 hours. If there are no willing staff to take the client to the bathroom, they have to urinate etc. on the floor. Then they are abused for doing so. There are no blankets (suicide prevention) so there is no way to keep warm. This is especially hard if the client is from a remote area and unused to the air conditioning. The staff are required to observe the client via peep holes in the doors, further alienating the clients.

This environment is very unsuitable for Aboriginal clients (Nagel, Thompson, \& Spencer, 2008) and it is important to try to get them assessed and discharged from this type of unit as soon as possible. To stay where there is constant observation for Aboriginal people who live under the 'Public Gaze' all the time is horrendous and increases paranoia and anxiety. If the client is assessed after being in here for some time, the assessor will not always consider the effects of being 'in the lock-up' and label the client non-compliant, non-cooperative etc.

There are two designated 'mental health' beds in the regional hospital. These two beds are in single rooms with a shared TV room. They are comfortable, but still have the glass walls and an enclosed veranda and look like prison cells. Getting a client into these beds is like striking oil in your backyard. The clients have to be 'specialled' and this nursing cost comes out of the ward budget, so it is very difficult to convince the manager they need to be admitted. These beds are not for treatment issues - they are for clients waiting transfer to the state capital's major mental health hospital: an hour's air travel or six hours in a vehicle. (For treatment in the region, a client must use the private hospital, although I have never known there to be an Aboriginal client in this facility.) After finding a bed on the ward, organising for a nurse special, arranging transport to the hospital, handing over the client to the major hospital's registrar and waiting for a bed there to become available, the client usually runs away down the unlocked fire escape stairs, conveniently located immediately next to the mental health rooms, as soon as the nurse goes for a break. 


\section{The client's journey: assessment}

After the pre-admission stage, the admitting practitioner needs to perform an assessment. There are a number of different assessment tools in the services in the region e.g., the State Mini Mental or the Kessler 10 (K10) etc. Each of these is a useful tool, but is not configured for cultural appropriateness. For example, the K10 is designed to be a non-specific (i.e. symptoms only without diagnosis) measure of psychological distress using nervousness, agitation, psychological fatigue and depression scores (Coombs, 2005). It has been used for assessing Aboriginal people in WA and in the National Survey for Social and Emotional Wellbeing (Australian Health Ministers' Advisory Council, 2008). The issue for the Aboriginal clients where I work is simple: they will score high on all these scores and it doesn't necessarily mean a mental health disorder. To be in an Aboriginal client's position (powerless, no knowledge, dependent on the other's approval etc) is very frightening and the scores may be artificially elevated and not count that which they are supposed to count. This will give false positives in terms of diagnosis.

The admission paperwork for the health service has a pathway-type set of considerations on admission, however, none allows operationally for cultural differences. To understand 'not-normal', one needs to be fully cognizant of what is normal, for self and other (Nagel, Robinson, Trauer, \& Condon, 2008). For example, one young man with paranoid schizophrenia who was comforted by talking to his (deceased) mother was labelled as 'hallucinating'. When I told his nurse that I often talk to my (deceased) mother, and that it was a cultural consideration, she reported me to the health service manager as having a mental health issue myself (I 'told' my mother - we both laughed!).

\section{Clinician as cultural translator for client/service}

If I am writing a formal assessment report, I use the Australian College of Mental Health Nurses' Mental State Examination (Australian College of Mental Health Nurses, 2009), with the usual markers of appearance and behaviour, mood, affect, speech, thought form, thought content, perception, insight/judgement and cognition. I assess a client through an Aboriginal 'lens', however, and therefore I don't always get the same results as another clinician might. If I am working with the AMS or, if appropriate, I like to use the 'Stay Strong' Remote Mental Health Care Plan (Nagel, 2007). This tool gives the client control over what is recorded, I can give a copy to the client if possible as well, and it is anecdotally more robust than some of the other Aboriginal-specific assessment tools, e.g. the Kimberly Aboriginal Cognitive Assessment (LoGiudice et al., 2006). However, it is not popular in main-stream usage.

These issues are ameliorated with a culturally proficient practitioner using an assessment process that considers what 'normal' looks like (Vicary \& Andrews, 2001). For example, a common community coping behaviour is a collective response, where vicarious grief and loss are felt by the whole community. A whole community might 'shut down' after the loss of an Elder or a child. The community will host other Aboriginal people and there will often be a large funeral. I witnessed an event such as this earlier in the year, where an Elder was taken to the nursing post having suffered a cardiac arrest at a sporting event. The nurse on duty attempted to resuscitate the man, but was unsuccessful. Given there are no mortuary facilities in 
most remote communities, the deceased person was flown to a larger centre, declared deceased and then had to wait until return to the community could be arranged, with costs involved to the family.

The nurse seemed to think the community would be 'out to get [her]' and asked for police reinforcements for the day of the funeral. The nursing post was not closed and the nurse did not attend the service (I made the cakes - about 100 - because I always come to a community prepared to be the cake-maker.) There was no issue with the nurse and the community. There was no issue with the police and the community. However, there were a lot of official requests for safety from the nurse and the non-Aboriginal community that were based on stereotypes and racism.

This same nurse also performed the mental health assessments for the entire local community and it was obvious that these behaviours - even though they are not related to mental health care - inform the community and influence their healthseeking behaviours. Assessments referred to me from this community were always that the client, if male, had drug-induced psychosis and, if female, had depression and anxiety. I had to send the BTH counsellor to this nursing post in response to community requests, as the nurse was supporting the embeddedness of an assimilation ethos revealed as paternalistic care and ethnocentrism (Syme, 2007). Refusing to look at social and emotional well-being and denying effects of the social determinants of mental health (employment, hope, food security, grief and loss etc) is parallel to denying care.

\section{Whole-of-community assessment}

I am often required to work in a discrete community to address a wholeof-community issue. In these cases, I use a community assessment scale developed by the WHO. This scale measures some of the social determinants of health and allows trends and tracking over time to demonstrate a change. It is not used by any Australian government program, even though the 'Close the Gap' program drops down from the WHO Social Determinants of Health program (WHO Social Determinants of Health Commission, 2008). This might not be the most effective measure, however, it gives quantitative data to people such as shire general managers a firm numerical measurement that they can use to determine funding in an evidencebased manner. Of course, it is still subjective, but this is acknowledged when discussing the results.

Sometimes, I am asked do an analysis for cultural appropriateness by a nonhealth organisation. For example, the shire library in the region's major town asked for some workshops for their staff and then for an assessment for cultural competency on their service. There are appropriate, published tools to do this (Westerman, 2004), but they are very expensive and therefore prohibitive. I used a Y analysis for this service (see Figure 1), as I have used it to assess cultural respect or proficiency in other organisations. It is very simple: you ask yourself what do you hear/see/feel when you enter a service and as you travel along the client continuum. If you walk into an in-patient setting and there are Aboriginal art-works or posters and informational flyers etc, you can get the sense that the service providers will have considered an Aboriginal viewpoint. If you see an Aboriginal person, you might feel more comfortable and if you hear positive comments, you will feel safe. I then pick out examples of positive and negative issues and feed this back to the organisation. 


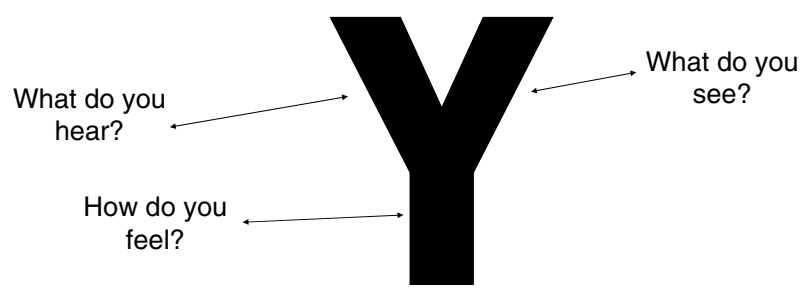

Figure 1. ' $\mathrm{Y}$ ' Analysis to measure organisational culture.

\section{The client's journey: recovery and discharge}

There are a myriad of issues as the client continues along the recovery journey, however, I do not very often deal with clients when they are doing well, or 'uneventful'. Nonetheless, I understand the issues are client compliance and access to information that fosters accuracy in diagnosis and I truly empathise with the clinicians trying so hard to make it better for Aboriginal people in the face of such odds and with minimal organisational support. It is challenging to work around this process, and AMHWs are often called out at night or after-hours to avoid using the police in this most inappropriate manner. This leads to burn-out in the workers, however. The burnout time for workers in Aboriginal services is high, as these positions are very hard on one's heart, and the communities often except the worker to be available at all hours (Parker, 2003).

Discharging to remote areas is also extremely challenging. There are often no resources, no guarantee of service provision or appropriateness in remote areas in my region. There is often a lack of social support, no ability to travel for follow-up appointments and minimal communication between the inpatient service and health care clinics in the region (Keightley et al., 2009). Often, there is stigma attached to obtaining medication. For example, the AMS in the regional centre provides an outreach service. This is a campervan converted to a mini-clinic and drives to the remote centres, parks in a main street and Aboriginal clients line up along the street to access the services or obtain their medication. This denies any possibility of confidentiality for mental health clients. At times, the mobile clinic staff have to 'track down' a client to give them medication. Sometimes, due to cultural considerations, e.g. mother-in-law avoidance or attending sorry business, the client might not be in the town on the day/s the clinic van is there and medication is not allowed to be 'picked up' on behalf of another.

The distances involved, (e.g. from the State's inpatient facility in Perth to the largest town in this region is over $500 \mathrm{kms}$ ) preclude home visits from acute care staff. This implies the skill required will be in-house in remote clinics, which might not be the case. I have also, unfortunately, had clients discharged after being transferred down on a 'schedule' - or forced transfer - only to be discharged with no money, no clothes to return in and to families and communities that might not even have a phone, much less the resources to buy a ticket on a bus. This means clients are at threat of becoming one of the 'parkies' - or homeless - Aboriginal people in the main towns awaiting resources to return home. It is obvious that this is detrimental to continued recovery of clients.

Shame is an Aboriginal concept implying loss of face. It is a strong negative sense and occurs when an Aboriginal person feels they have stepped outside of self's boundaries (Munns, 1998). This feeling is a threat to fracturing relationships, as 
individuals can 'shame' families and communities. To remote Aboriginal people, kinship ties are very important and the threat of shaming extended family is painful and powerful for Aboriginal people. It cannot be argued with - if the client feels it or fears it, it requires great skill from clinicians to manage it (Valance \& Tchacos, 2001). Clients feeling this shame are unlikely to seek or gain family support and are at a great risk of relapse. The need for a cycle of cultural proficiency is quintessential to recovery success, but not always readily available.

\section{Applying cultural proficiency: organisations and clinicians}

Organisations can set the standard for cultural competency by ensuring that their organisation's Mission, Vision and Values statements reflect social justice issues. The organisation can embed cultural proficiency in all the job descriptions and recruitment processes, with applicants being required to articulate how they demonstrate this skill. The manager/s could undertake a Y analysis of the organisation, but especially the 'shop fronts', where there is maximum articulation with the public. These analyses need then to be reviewed and actioned (e.g. increase Aboriginal art, ensure environment allows outside interviewing etc). It would decrease the institutionalised racism if local elders were used as brokerage for local community in the same manner as Maori Kaumatua and Kaitoko whanau (community liaison officers) are used in Aotearoa's mental health units.

Organisations and health service administrators need to place the same importance on this training as they would on other skill-acquisition training, e.g. cannulation. Policies and practices of each service need to reflect cultural competency (Jones \& Brideson, 2009). It is not hard to find resources, local experts and/or professional guidance on the appropriate interventions for Aboriginal people, but it is challenging to get compliance or motivation to do so at a personnel level. Managers need to be charged with this responsibility. Compliance to State and Commonwealth data collections must be mandated (to increase identification of Indigeneity) and increase the body of evidence.

Clinicians need to have tertiary qualifications in Aboriginal Social and Emotional Wellbeing and this should be essential criteria for mental health practitioners working in Aboriginal communities. Assessment tools, clinical pathways etc. should be modified to reflect local community needs. This requires the involvement of Aboriginal people in the decision-making for health service, in all arenas. Aboriginal Mental Health Worker positions need to be increased, training provided and support given at operational and strategic levels.

All levels of staff in health, policing, forensic and community positions need to attend Cultural Proficiency training and be able to operationalise the training (Harris \& Robinson, 2007) and be accredited as proficient. Following Bloom's taxonomy of learning domains, there are three key areas - knowledge, skills and behaviours. One can teach a practitioner that there is a different method of talking to Aboriginal Elders (i.e. give the knowledge) and even mentor them in having these conversations (i.e. give the skill) but if their attitude remains off-hand or paternalistic, then the behaviours will match. I have seen a practitioner interact with an Aboriginal client, then walk out of the room and tell me how she 'can't understand how Aboriginal people can get themselves into such a mess', as though my being a co-worker somehow transmogrifies my position from 'Aboriginal' to coconspirator in her overt paternalism (read: racism!). A health practitioner with this 
attitude, regardless of knowledges or skills, will forever be ineffective and unaware of their impotence in therapeutic relationships.

\section{Conclusion: proficiency in the organisation and the professional}

Cultural proficiency is the ability to apply and demonstrate the theories of cultural competency, respect and safety. It needs to be considered as important as any other clinical skill. There are always two main issues when looking at appropriateness of services for Aboriginal people - processes and people - and they are intertwined all along the continuum of care, with no definitive 'starting point'. To 'close the gap' in service delivery, health practitioners need to be not only culturally proficient, but they need to have social justice as a core value.

Quality service for Aboriginal people in mental health care needs to be mandated at every level of service delivery in order to close the gap and not just build bridges. It is evidently not enough that we are left to hope for a practitioner with views enlightened enough to be culturally sensitive or even aware. The current state of Aboriginal mental health clearly indicates urgent but appropriate changes in health care delivery. This will require a concerted effort across the continuum of care as amelioration of one of the poor social determinants of Aboriginal social and emotional well-being.

\section{Acknowledgements}

I would like to acknowledge Bill McCann and Dee Hellsten (USQ), for the outstanding contributions they make to Aboriginal Mental Health in Australia.

\section{Notes on contributors}

Aunty Kerrie Doyle is an Aboriginal woman, who grew up on Darkinjung land in NSW. She is peripatetic and has worked and studied across Australia. Currently she is an Assistant Professor in Public Health at the University of Canberra.

\section{References}

Australian Institute of Aboriginal and Torres Strait Islander Studies. (2010). Australian Aboriginal English. Retrieved July 7, 2010, from http://coombs.anu.edu.au/WWWVLPages/ AborigPages/LANG/WA/4_7_1.htm

Australian Bureau of Statistics. (2010). Australian year book, 2009. Canberra: Government Printers.

Australian Health Ministers' Advisory Council. (2008). Aboriginal and Torres Strait Islander health performance framework 2008 summary. Canberra: AHMAC, Government Printers.

Australian Institute of Health and Welfare. (2008). National community mental health care database: Mental health services in Australia 2005-2006. Canberra: Government Printers.

Berry, S.L., \& Crowe, T. (2009). A review of engagement of Indigenous Australians within mental health and substance abuse services. Advances in Mental Health, 8(1), 16-27.

Brideson, T. (2004). Moving beyond a 'seasonal work syndrome' in mental health: Service responsibilities for Aboriginal and Torres Strait Islander populations. Australian e-Journal for the Advancement of Mental Health, 3(3) 99-102.

Brunero, S., Lamont, S., \&; Fairbrother, G. (2009). Using and understanding consumer satisfaction to effect an improvement in mental health service delivery. Journal of Psychiatric \& Mental Health Nursing, 16(3), 272-278. 
Cleworth, S., Smith, W., \& Sealey, R. (2006). Grief and courage in a river town: A pilot project in the Aboriginal community of Kempsey, New South Wales. Australasian Psychiatry, 14(4), 390-394.

Coombs, T. (2005). Kessler 10 manual. Sydney: NSW Institute of Psychiatry.

Draper, G.K., Somerford, P.J., \& Pilkington, A.A.G. (2009). What is the impact of missing Aboriginal status on mortality estimates? An assessment using record linkage in Western Australia. Australian and New Zealand Journal of Public Health, 33(4), 325-331.

Drury, N., \& Munro, T. (2008). Crisis engagement in mental health: A New Zealand Maori contribution. International Journal of Mental Health Nursing, 17(5), 317-325.

Duke, M. (2007). The dawn of Aboriginal psychiatry. Australasian Psychiatry: Bulletin of the Royal Australian and New Zealand College of Psychiatrists, 15(4), 305-309.

Dunbar, J.A., Hickie, I.B., \& Wakerman, J. (2007). New money for mental health: Will it make things better for rural and remote Australia? Medical Journal of Australia, 186(11), 587-589.

Eley, D., Young, L., \& Hunter, K. (2007). Perceptions of mental health service delivery among staff and Aboriginal consumers: It's still about communication. Australasian Psychiatry, $15(2), 130-134$.

Garvey, D. (2008). A review of the social and emotional wellbeing of Aboriginal Australian peoples: Considerations, challenges and opportunities. Retrieved July 3, 2009, from http:// www.healthinfonet.ecu.edu.au/sewb_review

Geanellos, R. (2005). Undermining self-efficacy: The consequence of nurse unfriendliness on client on client well-being. Collegian, 12(4), 9-14.

Gorman, D., \& Ward, R., (2008). Developing suicide prevention expertise with Aboriginal communities. International Journal of Mental Health Nursing, 17, A11-A11.

Harris, A., \& Robinson, G. (2007). The Aboriginal Mental Health Worker Program: The challenge of supporting Aboriginal involvement in mental health care in the remote community context. Australian e-Journal for the Advancement of Mental Health, 6(1), $1-11$.

Haswell-Elkins, M., Sebacic, T., Hunter, E., \& Mar, M. (2007). Challenges of measuring the mental health of Aboriginal Australians: Honouring ethical expectations and driving greater accuracy. Australasian Psychiatry, 15(Suppl.1), S29-S33.

Hunter, E. (2007). Disadvantage and discontent: A review of issues relevant to the mental health of rural and remote Aboriginal Australians. Australian Journal of Rural Health, $15(2), 88-93$.

Jones, A. (2009). Understanding key concerns for patient involvement with mental health services: A report on a study visit to Australia. Mental Health Nursing, 29(4), 13-17.

Jones, C., \& Brideson, T. (2009). Using policy and workforce development to address Aboriginal mental health and well-being. Australasian Psychiatry, 17(Suppl. 1), S72-S74.

Keightley, M.L., Ratnayake, R., Minore, B., Katt, M., Cameron, A., White, R., et al. (2009). Rehabilitation challenges for Aboriginal clients recovering from brain injury: A qualitative study engaging health care practitioners. Brain Injury, 23(3), 250-261.

Knudsen, H. (2009). Smoking cessation services in adolescent substance abuse treatment: Opportunities missed? Journal of Drug Issues, 39(2), 257-276.

Larson, A., Gillies, M., Howard, P.J., \& Coffin, J. (2007). It's enough to make you sick: The impact of racism on the health of Aboriginal Australians. Australian and New Zealand Journal of Public Health, 31(4), 322-329.

Lee, K.S.K., Clough, A.R., \& Jaragba, M.J. (2008). Heavy cannabis use and depressive symptoms in three Aboriginal communities in Arnhem Land, Northern Territory. Medical Journal Of Australia, 188(10), 605-608.

Lemstra, M., Neudorf, C., \& Mackenbach, J. (2008). Risk indicators for depressed mood in youth: Limited association with Aboriginal cultural status. Paediatrics \& Child Health, 13(4), 285-290.

LoGiudice, D., Smith, K., Thomas, J., Lautenschlager, N.T., Almeida, O.P., Atkinson, D., et al. (2006). Kimberley Aboriginal Cognitive Assessment tool (KICA): Development of a cognitive assessment tool for older Aboriginal Australians. International Psychogeriatrics, 18(2), 269-280.

Maffei, C., Shea, J., \& Stewart, M. (2003). Measuring patient satisfaction. Psychiatric Services, 54,1411 . 
Medicine Australia. (2008). Assessment in Aboriginal health. Retrieved July 8, 2009, from http://www.medicineau.net.au/clinical/abhealth/abhealt1345.html

Australian College of Mental Health Nurses. (2009). Mental state examination. Retrieved June 6, 2009, from www.acmhn.org

Munns, G. (1998). A lot of them get so shamed: Koori students, risks, shame and the classroom curriculum. SET, $2,5$.

Nagel, T., Robinson, G., Condon, J., \& Trauer, T. (2009). Approach to treatment of mental illness and substance dependence in remote Aboriginal communities: Results of a mixed methods study. Australian Journal of Rural Health, 17(4), 174-182.

Nagel, T., Robinson, G., Trauer, T., \& Condon, J. (2008). An approach to treating depressive and psychotic illness in Aboriginal communities. Australian Journal of Primary Health, 14(1), 17-24.

Nagel, T., Thompson, C., \& Spencer, N. (2008). Challenges to relapse prevention: Psychiatric care of Aboriginal in-patients. Australian e-Journal for the Advancement of Mental Health, $7(2), 1-9$.

O'Brien, A. (2006). Moving toward culturally sensitive services for Aboriginal people: A nonAboriginal mental health nursing perspective. Contemporary Nurse, 21(1), 22-31.

Parker, R. (2003). The indigenous mental health worker. Australian Psychiatry, 11(3), 295-297.

Raphael, B., \& Swan, P. (1997). The mental health of Aboriginal and Torres Strait Islander people. International Journal of Mental Health, 26(3), 9-22.

Nagel T. (2007). Remote Aboriginal Mental Health Stay Strong Plan. AIMHhi. Retrieved July ..., 2009, from http://menzies.edu.au/research/healing-and-resilience/mental-health/aimhint-australian-integrated-mental-health-initiativ

Papps, E., \& Ramsden, I. (1996). Cultural safety in nursing: The New Zealand Experience. International Journal for Quality in Health Care, 8(5), 491-497.

Sheldon, M. (2001). Psychiatric assessment in remote Aboriginal communities. Australian \& New Zealand Journal of Psychiatry, 35(4), 435-442.

Sheldon, M. (2010). Reviewing psychiatric assessment in remote Aboriginal communities. In N. Pardie, P. Dudgeon, \& R. Walder (Eds.) Working together: Aboriginal and Torres Strait is lander Mental Health and Wellbeing Principles and Practice. Common wealth of Austraila.

Smith, K., Flicke, L., Lautenschlager, N.T., Almeida, O.P., Atkinson, D., Dwyer, A., et al. (2008). High prevalence of dementia and cognitive impairment in Aboriginal Australians. Neurology, 71(19), 1470-1473.

Syme, V.L. (2007). The nature of the tensions and disjunctures between Aboriginal understandings of and responses to mental health and illness and the current mental health system. Dissertation Abstracts International: Section B: The Sciences and Engineering, 65(3-B), 2004-1241.

Vallance, R., \& Tchacos, E. (2001, December). Research: A cultural bridge. Paper presented at the Australian Association for Research in Education (AARE) Conference, Fremantle, WA.

Vicary, D., \& Andrews, H. (2001). A model of therapeutic intervention with Aboriginal Australians. Australian \& New Zealand Journal of Public Health, 25(4), 349-351.

Vicary, D., \& Bishop, B.J. (2005). Western psychotherapeutic practice: Engaging Aboriginal people in culturally appropriate and respectful ways. Australian Psychologist, 40(1), 8-19.

Western Australia Mental Health Act. (1996). Retrieved September 14, 2009, from http://www. mhrbwa.org.au/publications/pdfs/The_Mental_Health_Act1996.pdf

Wand, A.P.F, Corr, M.J., \& Eades, S.J. (2009). Liaison psychiatry with Aboriginal and Torres Strait Islander peoples. Australian and New Zealand Journal of Psychiatry, 43(6), 509-517.

Webster's online dictionary. (1939). Retrieved July 14, 2009, from http://www.websters-onlinedictionary.org/

Westerman, T.G. (2004). Engagement of Aboriginal clients in mental health services: What role do cultural differences play? Australian e-Journal for the Advancement of Mental Health, $3(3), 88-94$.

World Health Organisation Social Determinants of Health Commission. (2008). Closing the gap in a generation: Health equity through action on the social determinants of health. Geneva: World Health Organisation. 